\title{
Evaluation and Characterization of Seedling Resistances to Stem Rust Ug99 Races in Wheat-Alien Species Derivatives
}

\author{
S. S. Xu, ${ }^{\star}$ Y. Jin, D. L. Klindworth, R. R.-C. Wang, and X. Cai
}

\begin{abstract}
Stem rust (caused by Puccinia graminis Pers.:Pers. f. sp. tritici Eriks. \& E. Henn.), a devastating disease of wheat (Triticum aestivum L.), was effectively controlled worldwide for the past $50 \mathrm{yr}$ by deployment of stem rust resistance $(\mathrm{Sr})$ genes in wheat cultivars. However, a new stem rust race, TTKSK (known as Ug99 or TTKS) that emerged in eastern Africa, is a cause of concern because it has broad virulence to currently deployed $\mathrm{Sr}$ genes. To identify potentially new sources of effective $\mathrm{Sr}$ genes against Ug99, we evaluated and characterized the seedling responses to TTKSK of 62 wheat lines derived from crosses of common or durum wheat ( $T$. turgidum L. ssp. durum) with the species Thinopyrum junceum, Th. intermedium, Th. bessarabicum, Th. elongatum, Th. ponticum, Elymus rectisetus, Aegilops caudata, and Ae. speltoides. For stem rust evaluation, we first tested all lines for reactions to races TTTT and TTKSK. Lines initially showing resistance to TTKSK were then retested with eight races, including three races in the TTKS lineage (TTKSK, TTKST, and TTTSK) and five North American races (QFCS, QTHJ, RCRS, RKQQ, and TPMK). Thirty wheat-alien species derivatives had resistance to TTKSK, TTKST, and TTTSK. The comparisons of wheatalien species derivatives and their parental lines for reactions to different races suggested that 12 partial amphiploids or amphiploids and four disomic addition lines may carry novel genes for stem rust resistance. These resistant lines represent materials for introducing stem rust resistance genes into wheat breeding.
\end{abstract}

S.S. Xu and D. L. Klindworth, USDA-ARS, Northern Crop Science Lab., Fargo, ND 58105; Y. Jin, USDA-ARS, Cereal Disease Lab., Univ. of Minnesota, St. Paul, MN 55108; R.R.-C. Wang, USDA-ARS, Forage and Range Research Lab., Logan, UT 84322; X. Cai, Dep. of Plant Sciences, North Dakota State Univ., Fargo, ND 58105. Mention of trade names or commercial products in this article is solely for the purpose of providing specific information and does not imply recommendation or endorsement by the U.S. Department of Agriculture. Received 12 Feb. 2009. ^Corresponding author (steven.xu@ars.usda.gov).

Abbreviations: CIMMYT, International Maize and Wheat Improvement Center; CS, Chinese Spring; IT, infection type; LDN, Langdon.

$\mathrm{S}$ tem rust, Caused by Puccinia graminis Pers.:Pers. f. sp. tritici Eriks. \& E. Henn., is a major, devastating disease of common or bread wheat (Triticum aestivum L., $2 n=6 x=42$, AABBDD genome) and durum wheat (T. turgidum L. ssp. durum, $2 n=4 x=28$, AABB). Leonard and Szabo (2005) listed major losses to stem rust that occurred in the twentieth century, primarily before 1960, in Europe, China, Australia, and North America. By the 1990s, the incidence of stem rust had dramatically fallen, due in large part to the deployment of stem rust resistance $(S r)$ genes in cultivars (Singh et al., 2006). One of the most important Sr genes was Sr31, which was deployed worldwide in many cultivars (Singh et al., 2006). In 1999, virulence to Sr31 was detected in nurseries in Uganda (Pretorius et al., 2000) and the race was designated as Ug99. Based on the North American stem rust nomenclature system (Roelfs and Martens, 1988), Wanyera et al. (2006) designated this virulence type as TTKS. With the recent identification of new variants of TTKS, the original race Ug99 was redesignated as TTKSK (Jin et al., 2008b).

Published in Crop Sci. 49:2167-2175 (2009)

doi: 10.2135/cropsci2009.02.0074

(C) Crop Science Society of America

677 S. Segoe Rd., Madison, WI 53711 USA

All rights reserved. No part of this periodical may be reproduced or transmitted in any form or by any means, electronic or mechanical, including photocopying, recording, or any information storage and retrieval system, without permission in writing from the publisher. Permission for printing and for reprinting the material contained herein has been obtained by the publisher. 
Race TTKSK is causing alarm for three reasons. First, this race has broad virulence to currently deployed $\mathrm{Sr}$ genes (Jin et al., 2007; Singh et al., 2006). Jin and Singh (2006) found that among North American cultivars, only $16 \%$ of hard red spring wheats, $48 \%$ of hard red winter wheats, and $28 \%$ of soft winter wheats had resistance to race TTKSK. Second, race TTKSK has continued to evolve. In 2006-2007, variants of TTKSK, designated TTKST and TTTSK (i.e., with added virulence to Sr24 and $\operatorname{Sr} 36$, respectively) were detected in Kenya (Jin et al., 2008b; 2009). The third concern was the rapid movement of TTKSK from Africa. A predicted path for dispersal of TTKSK from eastern Africa to the Arabian Peninsula and ultimately to the Indian subcontinent, was proposed by Singh et al. (2006). Race TTKSK has closely followed this path, appearing in Yemen in 2006 (Jin et al., 2008a) and Iran in 2007 (Nazari et al., 2009).

Host resistance genes provide excellent control of stem rust. Thus, the most effective measure to prevent epidemics is to deploy $\mathrm{Sr}$ genes that are effective against TTKSK and its variants in wheat cultivars and breeding lines. Such an effort is currently being undertaken at the International Maize and Wheat Improvement Center (CIMMYT) and other wheat breeding programs (Singh et al., 2008). However, the number of $\mathrm{Sr}$ genes in wheat that are effective against TTKSK and its variants is limited. There is a need to expand the $S r$ gene resources by searching for further resistance genes in species related to, and crossable with, wheat. In the wheat gene pool, a number of progenitor and relative species are known to be potential sources of $\mathrm{Sr}$ genes. Among $50 \mathrm{Sr}$ genes listed in the current Catalogue of Gene Symbols for Wheat (McIntosh et al., 2008), 18 were derived from the progenitor and related species of wheat and 15 are effective against race TTKSK (Singh et al., 2006; Xu et al., 2008).

In our research program "Improvement of Hard Red Spring and Durum Wheat for Disease Resistance and Quality Using Genetics and Genomics," we have developed and collected a number of wheat-alien species derivative lines developed from crosses of common wheat or durum wheat with Aegilops speltoides Tausch $(2 n=2 x=14$, SS), Thinopyrum intermedium (Host) Barkworth \& D. R. Dewey $(2 n=6 x=42$, EEEEStSt or JJEEStSt) (Cauderon et al., 1973; Sun, 1981), Th. ponticum (Podp.) Z-W. Liu \& R.-C. Wang [syn. Agropyron elongatum (Host) Beauv., Elytrigia pontica (Podp.) Holub., Lophopyrum ponticum (Podp.) Á. Löve, $2 n=10 x=70$, EEEEEEEEEE] (Sun, 1981; Kibirige-Sebunya and Knott, 1983), Th. elongatum (Host) D.R. Dewey $(2 n=2 x=14$, EE) (Dvorák and Knott, 1974), Th. junceum (L.) Love $(2 n=6 x=42$, EEEEEE or JJJJEE) (Charpentier, 1992), Th. bessarabicum (Savul. \& Rayss) Á. Löve $(2 n=2 x=14, \mathrm{JJ})$ (Zhang et al., 2002), Ae. caudata L. [syn. Ae. markgrafii (Greuter) K. Hammer $(2 n=2 x=14$, CC)] (Bluethner et al.,1988), Elymus rectisetus (Nees) Á. Löve \& Connor $(2 n=6 x=42$, StStYYWW) (Xue and Wang,
1999), and Haynaldia villosa (L.) Schur (syn. Dasypyrum villosum, $2 n=2 x=14$, VV) (Chen et al., 1995). Most of these lines have been evaluated for resistance to several important wheat diseases such as tan spot [caused by the fungus Pyrenophora tritici-repentis (Died.) Drechsler, anamorph Drechslera triticirepentis (Died.) Shoemaker] (Oliver et al., 2006, 2008), Stagonospora nodorum blotch [caused by Stagonospora nodorum (Berk.) E. Castell. \& Germano, teleomorph Phaeosphaeria nodorum (E. Müll.) Hedjar] (Oliver et al., 2006, 2008), Fusarium head blight [Fusarium graminearum Schwabe, teleomorph Gibberella zeae (Schw.) Petch.] (Oliver et al., 2005), and barley yellow dwarf viruses (Banks et al., 1993; Zhang et al., 1996b). Although some of the lines were evaluated for resistance to several races of stem rust (Banks et al., 1993), the lines were not evaluated for resistance to TTKSK and its variants. In this study, we evaluated these wheat-alien species derivatives and their wheat parental lines for reaction to TTKSK and other races; we then discuss the possible source and novelty of the $S r$ genes in some of the resistant lines.

\section{MATERIALS AND METHODS Plant Materials}

Plant materials used in this study included 5 bread wheat cultivars and lines, 5 durum wheat cultivars and lines, 62 wheat-alien species derivatives (18 partial amphiploids, 7 amphiploids, 33 disomic addition lines, and 4 alien translocation lines), and 1 E. rectisetus accession (Table 1). The wheat or wheat-alien species derivative lines were originally developed and/or cytogenetically characterized in different research programs (see references in Table 1). 'Langdon' (LDN) durum-derived amphiploids and the LDN $5 \mathrm{D}(5 \mathrm{~B})$ disomic chromosome substitution line were developed by L.R. Joppa in the USDA-ARS, Northern Crop Science Laboratory, Fargo ND. The common wheat-Th. ponticum partial amphiploid SS5 (PI 604926) was a selection in a collection of interspecific hybrids assembled by W.J. Sando, currently held by the USDA germplasm collection. The wheat-Haynaldia villosa 6VS/6AL translocation line was originally developed by Chen et al. (1995). Three translocation lines (KS10-2, KS24-1, and LMq-28) with Sr43 were obtained from D.R. Knott, Department of Plant Sciences, University of Saskatchewan, Saskatoon, SK, Canada. All other partial amphiploids, amphiploids, disomic addition lines, and their parental lines were held by one of the authors (R. R.-C. Wang).

All the disomic addition lines (Table 1) were cytologically verified by mitotic chromosome counts on root tips (Xu and Joppa, 2000). The chromosome numbers of translocation line XC02B-93 and the T. aestivum/Th. intermedium partial amphiploid Zhong 8 were also determined.

\section{Stem Rust Races and Inoculation Procedure}

The following races (isolates), maintained at the USDA-ARS Cereal Disease Laboratory, St Paul, MN, were used for this study: TTTT (01MN89A-1-2), QFCS (06ND76C), QTHJ (75ND717C), RCRS (77ND82A), RKQQ (99KS76A-1), TPMK (74MN1407), TTKSK (04KEN156/04), TTKST (06KEN19v3), and TTTSK (07KEN24-4). All of the lines were tested for resistance to races TTTT and TTKSK. Lines initially 
Table 1. The wheat-alien species derivatives and their wheat parental lines used in this study.

\begin{tabular}{|c|c|c|c|c|c|}
\hline Type (no. of lines) & Line name or accession no. ${ }^{\dagger}$ & Pedigree or description & $2 n^{\ddagger}$ & No. of lines & References \\
\hline \multirow[t]{2}{*}{ Common wheat (5) } & LMPG-6 & Susceptible check & 42 & 1 & \\
\hline & $\begin{array}{c}\text { 'Alcedo', 'Chinese Spring' (CS), } \\
\text { 'Fukuhokomugi', 'Genaro' }\end{array}$ & $\begin{array}{l}\text { Parents of wheat-alien } \\
\text { species derivatives }\end{array}$ & 42 & 4 & \\
\hline \multirow[t]{5}{*}{ Durum wheat (5) } & ‘Langdon’ (LDN) & Parent of LDN-derived amphiploid & 28 & 1 & \\
\hline & LDN 5D(5B) & $\begin{array}{l}\text { LDN 5D(5B) disomic substitution line and } \\
\text { parent of LDN 5D(5B)-derived amphiploid }\end{array}$ & 29 & 1 & $\begin{array}{l}\text { Joppa and Williams (1988); } \\
\text { Li et al. (2006) }\end{array}$ \\
\hline & ST464-C1 & $\begin{array}{l}\text { ST464 derived monogenic } \\
\text { line postulated to carry Sr13 }\end{array}$ & 28 & 1 & Klindworth et al. (2007) \\
\hline & $\mathrm{KL}-\mathrm{B}$ & $\begin{array}{l}\text { 'Khapli' emmer derived monogenic } \\
\text { line postulated to carry Sr13 }\end{array}$ & 28 & 1 & Klindworth et al. (2007) \\
\hline & Rusty & Susceptible check & 28 & 1 & Klindworth et al. (2006) \\
\hline \multirow[t]{9}{*}{$\begin{array}{l}\text { Partial amphiploid } \\
\text { (18) }\end{array}$} & AJAP2, AJAP4, AJAP7, AJAP8 & CS/Thinopyrum junceum & 56,58 & 4 & $\begin{array}{l}\text { Charpentier (1992); } \\
\text { Wang et al. (2003) }\end{array}$ \\
\hline & Zhong 1, Zhong 4-7 & Triticum aestivum/Th. intermedium & 56 & 5 & Banks et al. (1993) \\
\hline & Zhong 8 & T. aestivum/Th. intermedium & & 1 & \\
\hline & TAF 46 & T. aestivum/Th. intermedium & 56 & 1 & Cauderon et al. (1973) \\
\hline & 78829 & T. aestivum/Th. intermedium & 56 & 1 & Zhang et al. (1996a,b) \\
\hline & $7631,693,784$ & T. aestivum/Th. ponticum & 56 & 3 & Zhang et al. (1996a,b) \\
\hline & SS5 (PI 604926) & $\begin{array}{l}\text { CS/Th. ponticum//Arlando/ } \\
\text { Leapland/Comet125 }\end{array}$ & 56 & 1 & Sando (Oliver et al., 2006) \\
\hline & $40767-1$ & T. aestivum/Th. ponticum & 56 & 1 & Zhang et al. (1996a,b) \\
\hline & OK 7211542 & T. aestivum/Th. ponticum & 56 & 1 & Sando (Zhang et al., 1996b) \\
\hline \multirow[t]{3}{*}{ Amphiploid (7) } & W95001 & CS/Th. bessarabicum & 56 & 1 & Zhang et al. (2002) \\
\hline & $\begin{array}{l}\text { J83Ae164, J83Ae598, } \\
\text { J83Ae663 }\end{array}$ & Langdon (LDN) / Ae. speltoides & 41,42 & 3 & L.R. Joppa (unpublished) \\
\hline & J83Ae613, J83Ae778, J83Ae793 & LDN 5D(5B)/Ae. speltoides & 42 & 3 & L.R. Joppa (unpublished) \\
\hline \multirow[t]{5}{*}{ Disomic addition (33) } & $\begin{array}{l}\text { AJDAj1- AJDAj9, AJDAj11, } \\
\text { HD3505, HD3508, HD3515 }\end{array}$ & CS/Th. junceum & 44 & 13 & $\begin{array}{l}\text { Charpentier (1992); } \\
\text { Wang et al. (2003) }\end{array}$ \\
\hline & Al (B)-A VIII (G) & Alcedo/Ae. caudata & 44 & 6 & $\begin{array}{l}\text { Bluethner et al. (1988); } \\
\text { Friebe et al. (1992) }\end{array}$ \\
\hline & A1026, A1034, A1057 & Fukuhokomugi/Elymus rectisetus JC1050 & 44 & 3 & Xue and Wang (1999) \\
\hline & $\begin{array}{c}\text { W5354, W7232, W7246, W5366, } \\
\text { W5326, W7250, W5336 }\end{array}$ & CS/Th. bessarabicum//Genaro (1J- 7J) & 44 & 7 & $\begin{array}{l}\text { Zhang et al. (2002); } \\
\text { Li et al. (2007) }\end{array}$ \\
\hline & W0622, W0889-W0891 & $\mathrm{CS}^{\star} 2 /$ Th. elongatum (1E, 2E, 6E, 7E) & 44 & 4 & $\begin{array}{l}\text { Dvořák and Knott (1974); } \\
\qquad \text { Li et al. (2007) }\end{array}$ \\
\hline \multirow[t]{2}{*}{ Translocation line (4) } & KS10-2, KS24-1, LMq-28 & $\begin{array}{l}\text { T. aestivum/Th. ponticum } \\
\text { translocation with Sr43 }\end{array}$ & 42 & 3 & $\begin{array}{l}\text { Kibirige-Sebunya } \\
\text { and Knott (1983) }\end{array}$ \\
\hline & XC02B-93 & $\begin{array}{c}\text { 6VS/6AL translocation/Yangmai5// } \\
\text { Sheng32109 }\end{array}$ & & 1 & Chen et al. (1995) \\
\hline
\end{tabular}

tLine name or accession numbers were based on the literatures as indicated in the references or were provided by seed providers.

¥The $2 n$ chromosome numbers were based on the literatures as indicated in the references or were provided by seed providers.

showing resistance to TTKSK were retested with the three races of the TTKS lineage (TTKSK, TTKST, and TTTSK), and the lines with adequate seed stocks were also tested with the five North American races (QFCS, QTHJ, RCRS, RKQQ, and TPMK). In each trial, 6 to 8 plants per line were inoculated following the procedure of Jin et al. (2007). Briefly, urediniospores were suspended in a light mineral oil and applied to 7- to 9-dold seedlings. Following inoculation, seedlings were incubated in the dark in a dew chamber for $14 \mathrm{~h}$ at $18^{\circ} \mathrm{C}$, followed by 3 to $4 \mathrm{~h}$ of fluorescent light. Plants were removed to a greenhouse at 18 to $20^{\circ} \mathrm{C}$ with a $16-\mathrm{h}$ photoperiod. Plants were scored for infection types (ITs) $14 \mathrm{~d}$ post inoculation using the system of Stakman et al. (1962). ITs 0, ; 1, 2, or any combination of these indicated resistance, and ITs 3 or 4 indicated susceptibility.

\section{RESULTS AND DISCUSSION}

Infection type data for the first test of all 73 lines with races TTTT and TTKSK and the chromosome numbers of all lines are shown in Table 2. The IT data for the TTKS lineage (TTKSK, TTKST, and TTTSK) and five North American races (QFCS, QTHJ, RCRS, RKQQ, and TPMK) in the second trial are listed in Table 3. There were four Th. junceum partial amphiploids in the first trial. Two (AJAP2 and AJAP4) were susceptible to TTKSK, but the other two (AJAP7 and AJAP8) gave ITs 2 and were also resistant to TTTT (Table 2). The partial amphiploids were produced using 'Chinese Spring' (CS) as the wheat parent (Charpentier, 1992); and since CS was susceptible to TTKSK, resistance to TTKSK in the partial amphiploids 
Table 2. Infection types produced by various amphiploids, partial amphiploids, disomic addition and translocation lines, and miscellaneous parental lines to races TTTT and TTKSK of Puccinia graminis f. sp. tritici.

\begin{tabular}{|c|c|c|c|c|}
\hline \multirow{2}{*}{ Line } & \multirow{2}{*}{ Pedigree } & \multirow{2}{*}{$2 n^{\dagger}$} & \multicolumn{2}{|c|}{ Infection types to race $\ddagger$} \\
\hline & & & TTTT & TTKSK \\
\hline 'Chinese Spring' (CS) & Triticum aestivum & 42 & 4 & 4 \\
\hline AJAP2 & CS/ Thinopyrum junceum partial amphiploid & 56 & 4 & 4 \\
\hline AJAP4 & CS/Th. junceum partial amphiploid & 56 & 3 & 4 \\
\hline AJAP7 & CS/Th. junceum partial amphiploid & 56 & $2++/ 3$ & 2 \\
\hline AJAP8 & CS/Th. junceum partial amphiploid & 58 & $2++$ & 2 \\
\hline AJDAj1 & CS/Th. junceum disomic addition & 44 & 4 & 4 \\
\hline AJDAj2 & CS/Th. junceum disomic addition & 44 & 4 & 4 \\
\hline AJDAj3 & CS/Th. junceum disomic addition & 44 & 4 & 4 \\
\hline AJDAj4 & CS/Th. junceum disomic addition & 44 & 4 & 4 \\
\hline AJDAj5 & CS/Th. junceum disomic addition & 44 & 4 & 4 \\
\hline AJDAj6 & CS/Th. junceum disomic addition & 44 & 4 & 4 \\
\hline AJDAj7 & CS/Th. junceum disomic addition & 44 & 4 & 4 \\
\hline AJDAj8 & CS/Th. junceum disomic addition & 44 & 4 & 4 \\
\hline AJDAj9 & CS/Th. junceum disomic addition & 44 & 4 & 4 \\
\hline AJDAj11 & CS/Th. junceum disomic addition & 44 & 4 & 4 \\
\hline HD3505 & CS/Th. junceum disomic addition & 44 & $2+$ & 2 \\
\hline HD3508 & CS/Th. junceum disomic addition & 44 & 3 & 4 \\
\hline HD3515 & CS/Th. junceum disomic addition & 44 & 4 & 4 \\
\hline Zhong 1 & T. aestivum/Th. intermedium partial amphiploid & 56 & $2+$ & $2+$ \\
\hline Zhong 4 & T. aestivum/Th. intermedium partial amphiploid & 56 & ; & ; \\
\hline Zhong 5 & T. aestivum/Th. intermedium partial amphiploid & 56 & 0 & ; \\
\hline Zhong 6 & T. aestivum/Th. intermedium partial amphiploid & 56 & 0 & ; \\
\hline Zhong 7 & T. aestivum/Th. intermedium partial amphiploid & 56 & 0 & ; \\
\hline Zhong 8 & T. aestivum/Th. intermedium partial amphiploid & 56 & ; & ; \\
\hline 78829 & T. aestivum/Th. intermedium partial amphiploid & 56 & & ; \\
\hline TAF 46 & T. aestivum/Th. intermedium partial amphiploid & 56 & & $2-;$ \\
\hline 7631 & T. aestivum/Th. ponticum partial amphiploid & 56 & & 2 \\
\hline 40767-1 & T. aestivum/Th. ponticum partial amphiploid & 56 & & $2+$ \\
\hline 693 & T. aestivum/Th. ponticum partial amphiploid & 56 & & 2 \\
\hline 784 & T. aestivum/Th. ponticum partial amphiploid & 56 & & ;2- \\
\hline OK 7211542 & T. aestivum/Th. ponticum partial amphiploid & 56 & & $2-$ \\
\hline SS5 (PI 604926) & CS/Th. ponticum//Arlando/Leapland/Comet125 & 56 & ;1/3; & ;1- \\
\hline W0622 & $\mathrm{CS}^{\star} 2 /$ Th. elongatum AABBDD + 1" (1E) & 44 & 3 & 3 \\
\hline W0889 & $\mathrm{CS}^{\star} 2 /$ Th. elongatum AABBDD + 1" (7E) & 44 & & 2 \\
\hline W0890 & $\mathrm{CS}^{\star} 2 /$ Th. elongatum AABBDD + 1" (6E) & 44 & & 4 \\
\hline W0891 & $\mathrm{CS}^{\star} 2 /$ Th. elongatum AABBDD + 1" (2E) & 44 & & 4 \\
\hline W5348 & CS/Th. bessarabicum AABBDDJJ amphiploid & 56 & $2+3-$ & $2+$ \\
\hline W5418 & ‘Genaro’ & 42 & $; 1$ & $2++$ \\
\hline W5354 & CS/Th. bessarabicum//Genaro (AABBDD + 1J) & 44 & 4 & $2+$ \\
\hline W7232 & CS/Th. bessarabicum//Genaro (AABBDD + 2J) & 44 & $3+$ & $2++$ \\
\hline W7246 & CS/Th. bessarabicum//Genaro (AABBDD + 3J) & 44 & 2 & 23 \\
\hline W5366 & CS/Th. bessarabicum//Genaro (AABBDD + 4J) & 44 & ; & 23 \\
\hline W5326 & CS/Th. bessarabicum//Genaro (AABBDD + 5J) & 44 & $3 / 2$ & 3- \\
\hline W7250 & CS/Th. bessarabicum//Genaro (AABBDD + 6J) & 44 & 3 & $2++$ \\
\hline W5336 & CS/Th. bessarabicum//Genaro (AABBDD + 7J) & 44 & 2 & 2 \\
\hline W2895 & Elymus rectisetus JC1050 & 42 & - & ; \\
\hline 'Fukuhokomugi' & T. aestivum & 42 & 4 & 4 \\
\hline A1026 & Fukuhokomugi/E. rectisetus JC1050 disomic addition & 44 & 4 & 4 \\
\hline A1034 & Fukuhokomugi/E. rectisetus JC1050 disomic addition & 44 & 4 & 4 \\
\hline A1057 & Fukuhokomugi/E. rectisetus JC1050 disomic addition & 44 & 4 & 4 \\
\hline
\end{tabular}


Table 2. Continued.

\begin{tabular}{|c|c|c|c|c|}
\hline \multirow{2}{*}{ Line } & \multirow{2}{*}{ Pedigree } & \multirow{2}{*}{$2 n^{\dagger}$} & \multicolumn{2}{|c|}{ Infection types to race $\ddagger$} \\
\hline & & & TTTT & TTKSK \\
\hline 'Alcedo' & T. aestivum & 42 & 4 & 4 \\
\hline $\mathrm{Al}(\mathrm{B})$ & Alcedo/Aegilops caudata disomic addition & 44 & 4 & 4 \\
\hline All (C) & Alcedo/Ae. caudata disomic addition & 44 & 2 & 2- \\
\hline Alll (D) & Alcedo/Ae. caudata disomic addition & 44 & $1+$ & $2-;$ \\
\hline$A V(E)$ & Alcedo/Ae. caudata disomic addition & 44 & 3- & 4 \\
\hline $\operatorname{AIV}(F)$ & Alcedo/Ae. caudata disomic addition & 44 & 4 & 4 \\
\hline AVIII (G) & Alcedo/Ae. caudata disomic addition & 44 & 4 & $3+$ \\
\hline XC02B-93 & 6VS/6AL translocation line/Yangmai5//Sheng32109 & 42 & 4 & 4 \\
\hline KS10-2 & KS10-2/4 'Thatcher' (Th. ponticum translocation; Sr43) & 42 & & ; \\
\hline KS24-1 & KS24-1 (Th. ponticum translocation; Sr43) & 42 & & ; \\
\hline LMq-28 & L 'Marquis' Marquis *6/28 Th. ponticum (Sr43) & 42 & & ;2- \\
\hline ‘Langdon’ (LDN) & T. turgidum ssp. durum & 28 & ; & $2 \mathrm{C}$ \\
\hline LDN 5D(5B) & LDN 5D(5B) disomic substitution & 29 & $1+$ & $2+$ \\
\hline J83Ae613 & LDN 5D(5B)/Ae. speltoides PI 369572 amphiploid & 42 & 1 & 2 \\
\hline J83Ae598 & LDN/Ae. speltoides PI 369581 amphiploid & 41 & ; & ; \\
\hline J83Ae164 & LDN/Ae. speltoides PI 369600 amphiploid & 42 & - & ; \\
\hline J83Ae663 & LDN/Ae. speltoides PI 369609 amphiploid & 42 & 1 & ; \\
\hline J83Ae778 & LDN 5D(5B)/Ae. speltoides PI 393494 amphiploid & 42 & 0 & 0 \\
\hline J83Ae793 & LDN 5D(5B)/Ae. speltoides PI 442448 amphiploid & 42 & ; & ; \\
\hline LMPG-6 & Susceptible hexaploid check & 42 & $3+$ & 4 \\
\hline Rusty & Susceptible durum wheat check & 28 & 4 & 4 \\
\hline KL-B & 'Khapli’ emmer-derived monogenic line postulated to carry Sr13 & 28 & 2- & $2++$ \\
\hline ST464-C1 & ST464-derived monogenic line postulated to carry Sr13 & 28 & 2- & $2+$ \\
\hline
\end{tabular}

TThe $2 n$ chromosome numbers of all disomic addition lines, translocation line XC02B-93, and partial amphiploid Zhong 8 were verified in this study; the chromosome numbers of all other lines were based on the literatures as indicated in the references or were provided by seed providers in Table 1 donors.

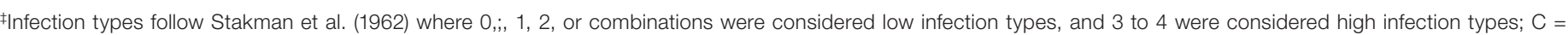
chlorosis; - = missing data.

was attributable to Th. junceum. When the $13 \mathrm{Th}$. junceum disomic addition lines were tested to TTKSK in the first test, only one line, HD3505, was resistant. In the second test, HD3505 was resistant to races in the TTKS lineage but was susceptible to most of the North American races. Partial amphiploids AJAP7 and AJAP8 were resistant to all races in the second trials (Table 3 ), indicating potentially useful sources of resistance different from the resistance gene in HD3505.

Five of the six Zhong-series wheat-Th. intermedium partial amphiploids in the first trial displayed IT ; to TTKSK (Table 2), whereas the sixth line, Zhong 1, gave IT 2+ (large 2 ). When these six lines were tested with the additional races, Zhong 1 was found to be susceptible to RKQQ and moderately susceptible to TTKST, TTTSK, and QTHJ (Table 3). However, the other five lines (Zhong 4-Zhong 8) were clearly resistant to all races, the highest IT being $2-$ (small 2). Whereas these lines should be valuable sources of stem rust resistance, their similar responses indicated they may have the same gene(s). The wheat-Th. intermedium partial amphiploids 78829 had fleck ITs to TTKSK in the first trail (Table 2), and it had fleck and ; ITs to TTKST and TTTSK, respectively, in the second trial (Table 3). The wheat-Th. intermedium partial amphiploid TAF46 was moderately resistant to TTKSK (2-;) in the first trial (Table 2). In the second trial (Table 3), it also was moderately resistant to TTKST (2+) and TTTST (2+), respectively. The and Baker (1970) showed that the resistance gene $\mathrm{Sr} 44$ was present in the $7 \mathrm{Ag}$ chromosome addition line derived from TAF46. This gene is the only designated wheat $\mathrm{Sr}$ gene derived from a TAF46-derived addition line (Cauderon et al., 1973; McIntosh et al., 1995; Friebe et al., 1996). Because Zhong 4, 5, 7, and 8 exhibited very different reactions to TTKSK, TTKST, and TTTSK from TAF46, they likely carry a $\mathrm{Sr}$ gene(s) different from $\mathrm{Sr} 44$ in TAF46.

These wheat-Th. intermedium partial amphiploids generally contain the complete wheat genome and seven pairs of chromosomes from Th. intermedium (Banks et al., 1993). Based on meiotic paring in the hybrids among eight partial amphiploids (Zhong 1-7 and TAF46), Banks et al. (1993) suggested that these partial amphiploids can be divided into three different groups: A (Zhong 1 and Zhong 2), B (Zhong 3-7), and TAF46. The partial amphiploids in group B differed by only one chromosome pair but differed from group A and TAF46 by two to five pairs of Th. intermedium chromosomes. Zhang et al. (1996b) reported that Zhong 3, 4, 5, and 7 carried five pairs of St-genome 
Table 3. Infection types produced by resistant amphiploids, partial amphiploids, and disomic addition lines, and translocation lines to eight races of stem rust.

\begin{tabular}{|c|c|c|c|c|c|c|c|c|}
\hline \multirow{2}{*}{ Line } & \multicolumn{8}{|c|}{ Infection type to race ${ }^{\dagger}$} \\
\hline & TTKSK & TTKST & TTTSK & QFCS & QTHJ & RCRS & RKQQ & TPMK \\
\hline AJAP7 & 2 & 2 & 2 & $2+$ & 2 & 2 & 2 & $2++$ \\
\hline AJAP8 & $2+$ & $2+$ & $2+$ & 2 & 2 & 2 & $22+$ & $2++$ \\
\hline HD3505 & ;2- & $3-$ & $2-$ & 2 & 4 & $2-/ 4$ & 3 & 4 \\
\hline Zhong 1 & $2+$ & $3-$ & $3-$ & 2 & 3 & 2 & $3+$ & $2+$ \\
\hline Zhong 4 & 0 & ; & ; & ; & ; & ; & ; & ; \\
\hline Zhong 5 & ; & ; & ; & ; & 0 & ; & $2-$ & ; \\
\hline Zhong 6 & ; & ; & ; & 0 & ; & ; & $2-$ & $2-$ \\
\hline Zhong 7 & ; & ; & ; & 0 & 0 & ; & $2-;$ & 0 \\
\hline Zhong 8 & ; & ; & ; & ; & ;2- & ; & $2-$ & ; \\
\hline 78829 & ;2- & ; & ; & & & & & \\
\hline TAF46 & $2+$ & $2+$ & $2+$ & & & & & \\
\hline 7631 & $2+$ & $2+$ & $3-$ & & & & & \\
\hline $40767-1$ & ;/2+ & ;/3-; & ;/3- & & & & & \\
\hline 693 & $2+$ & $2+$ & $2+$ & & & & & \\
\hline 784 & ; & 0 & ; & & & & & \\
\hline OK721142 & 2 & 2 & 2 & & & & & \\
\hline W0889 & 2 & $2+$ & $2+$ & & & & & \\
\hline SS5 & ;2- & 2 & 2 & 0 & 0 & $2-$ & ; & ; \\
\hline W5336 & $2-$ & $2-$ & $2-$ & ; & ; & ; & ; & 2 \\
\hline W5418 & 3 & 3 & 3 & 0 & 2 & $2-$ & $2-$ & $2-$ \\
\hline All (C) & 2 & 2 & $2+$ & ; & $2-$ & 2 & $2-$ & $2-$ \\
\hline Alll (D) & ;12- & ;2- & ; & ; & $3-$ & $x$ & 0 & $1 \mathrm{~N}$ \\
\hline KS10-2 & ; & ;2+ & ; & & & & & \\
\hline KS24-1 & ; & ;2+ & ;2 & & & & & \\
\hline LMq-28 & ; & ;2+ & ;2- & & & & & \\
\hline J83Ae613 & - & $2-$ & $2-$ & ; & ; & ; & ; & 1 \\
\hline J83Ae598 & ; & ; & ; & ; & - & ; & - & ; \\
\hline J83Ae164 & ;2- & ;2- & - & 0 & ; & ; & ; & 1 \\
\hline J83Ae663 & ;2- & - & 0 & 0 & ; & ; & ; & ; \\
\hline J83Ae778 & 0 & ; & 0 & 0 & ; & ; & - & ; \\
\hline J83Ae793 & ;2- & ;2- & ; & - & 0 & 0 & ; & ; \\
\hline
\end{tabular}

†Infection types follow Stakman et al. (1962) where 0, ;, 1, 2, or combinations were considered low infection types, and 3 to 4 were considered high infection types; $\mathrm{X}=$ mesothetic; $\mathrm{N}=$ necrotic; - = missing data.

‡Wheat cultivar Genaro (W5418) was listed for comparison of its response to stem rust with Th. bessarabicum $7 \mathrm{~J}$ disomic addition line (W5336).

chromosomes, one St/E Robertsonian translocation, and one St/E intercalary translocation, whereas Zhong 6 carried six pairs of St-genome chromosomes and one St/E Robertsonian translocation. However, TAF46 carried four pairs of E-genome and three pairs of St-genome chromosomes. Thus, Zhong 4, 5, 6, and 7 might carry the same $S r$ gene(s) due to their similar chromosome complements. Because Zhong 8 gave very similar ITs to Zhong 4, 5, 6, and 7 with all nine races (Table 2 and 3), it probably carries a similar set of Th. intermedium chromosomes to the five B group accessions. Thus, each of these partial amphiploids likely carries a novel gene(s) for a high level of stem rust resistance. Because neither parent was available for our tests, there is a slight possibility that the resistance was derived from a hexaploid wheat parent.
Six partial amphiploids (7631, 407671, 693, 784, OK 7211542, and SS5) derived from $T h$. ponticum were included in the study (Tables 2 and 3). They were all resistant to TTKSK in the first test. In the second test, 784 gave similar high levels of resistance reactions to TTKSK, TTKST, and TTTSK as Zhong 4, Zhong 5, Zhong 6, Zhong 7, and Zhong 8, whereas the responses of other five lines were similar to Zhong 1 and TAF46 (Table 3). Zhang et al. (1996a,b) reported that 784 and 40767-1 contained 21 pairs of A, B, D chromosomes, 6 pairs of St chromosomes, and 1 pair of E chromosomes; OK 7211542 contained 20 pairs of A, B, D chromosomes, 7 pairs of St chromosomes, and 1 pair of E chromosomes; and 7631 and 693 contained 20 pairs of wheat chromosomes and 8 pairs of E-genome chromosomes. The partial amphiploid SS5 (PI 604926) carries $14 \mathrm{Th}$. ponticum chromosomes and 42 wheat chromosomes, but the genome identities of the seven pairs of Th. ponticum chromosomes have not been determined (Oliver et al., 2006). Similar to the wheatTh. intermedium partial amphiploids, these wheat-Th. ponticum partial amphiploids may be a source of novel genes for stem rust resistance.

Four disomic addition lines derived from Th. elongatum were included in the tests (Tables 2 and 3). They carried chromosomes 1E, 2E, 6E, and 7E from Th. elongatum. Only W0889, the 7E disomic addition line, was resistant to TTKSK, TTKST, and TTTSK (Tables 2 and 3). Three of the stem rust resistance genes, that is, Sr25 and Sr43 from Th. ponticum and Sr44 from Th. intermedium, involved group 7 chromosome translocations (Knott, 1988; Friebe et al., 1996). It is possible that the 7E disomic addition line may carry a $\mathrm{Sr}$ gene that is the same as one of the three $\mathrm{Sr}$ genes $(\mathrm{Sr} 25$, Sr43, and Sr44) derived from group 7 chromosomes of Th. ponticum and Th. intermedium.

A CS-Th. bessarabicum amphiploid (W5348) and disomic addition lines for all seven J-genome chromosomes, were tested (Tables 2). The CS-Th. bessarabicum amphiploid gave IT 2+ to TTKSK in the first trial. The ITs of all seven disomic addition lines were similar to 'Genaro' (W5418), a wheat parent of the disomic addition lines. Furthermore, when tested with TTKSK, TTKST, and TTTSK in the second trial, with the exception of the 7J addition line W5336, all disomic additions were susceptible. The $7 \mathrm{~J}$ addition line 
W5336 had similar ITs to races QFCS and TPMK to Genaro, but the addition line had much lower ITs to the other six races than Genaro (Table 3), suggesting that chromosome 7J may carry a resistance gene(s) different from that in Genaro. Because stem rust resistance genes from Th. bessarabicum have not been reported in the literature, the Th. bessarabicum 7J addition line may be a novel source of stem rust resistance.

Elymus rectisetus accession JC1050 gave IT ; to TTKSK (Table 2). There were three wheat $-E$. rectisetus disomic addition lines in the first trial, and all were susceptible to both TTKSK and TTTT, indicating that the resistance gene(s) in E. rectisetus must be located on chromosome(s) other than those present in the disomic addition lines.

The Ae. caudata disomic addition lines were derived from crosses to T. aestivum cultivar Alcedo. Alcedo was susceptible to TTKSK, so any Ae. caudata disomic addition line with resistance to TTKSK must have a resistance gene(s) located on an Ae. caudata chromosome. Disomic addition lines AII and AIII containing the Ae. caudata chromosomes C and D, respectively, were resistant to TTKSK (Table 2). AII (C) was resistant to all races in the second trial, whereas AIII (D) was resistant to all races except QTHJ (IT 3-) and had a mesothetic (X) reaction to RCRS (Table 3), suggesting that the two addition lines may carry different resistance genes. Friebe et al. (1992) suggested that the $A e$. caudata chromosomes $\mathrm{C}$ and $\mathrm{D}$ may correspond to the chromosomes within the homoeologous group 5 and 6 , respectively. Because stem rust resistance genes from Ae. caudata have not been reported previously, AII (C) and AIII (D) are potential sources of novel resistance genes.

The three translocation lines (KS10-2, KS24-1, and LMq-28) carrying Sr43 derived from Th. ponticum were resistant to TTKSK, TTKST, and TTTSK (Table 2 and 3). The lines KS10-2 and KS24-1 had slightly higher levels of resistance than LMq-28, which may be attributed their 'Thatcher' background (Jin and Singh, 2006). LMq-28 carries Sr43 in a 'Marquis' background (Knott et al., 1977; Kibirige-Sebunya and Knott, 1983), and Marquis is known to carry $\operatorname{Sr} 7$, Sr18, Sr19, and $\operatorname{Sr} 20$ (Anderson et al., 1971). Since all four genes are ineffective against TTKSK (Jin et al., 2007), the reaction of LMq-28 to TTKSK and its variants probably correctly indicates the IT of these races to Sr43.

Among the wheat relatives, Ae. speltoides has been an excellent source of genes for stem rust resistance. Three Sr genes, Sr32 (Friebe et al., 1996), Sr39 (Friebe et al., 1996), and Sr47 (Faris et al., 2008), have been transferred into common wheat and durum wheat. All three confer resistance to TTKSK (Jin et al., 2007; Faris et al., 2008). In this study, six amphiploids (J83Ae598, 164, 613, 663, 778, and 793) involving Ae. speltoides as the alien parents and either Langdon or Langdon 5D(5B) disomic substitution line as the tetraploid wheat parent were tested (Tables 2 and 3). All six amphiploids exhibited high levels of resistance with IT; predominating in the test (Tables 2 and 3).
Langdon derives stem rust resistance from 'Khapli' emmer (Heermann and Stoa, 1956), the source of Sr13 (Knott, 1962). Hexaploid monogenic-Sr lines carrying $\mathrm{Sr} 13$ gave seedling IT 2+ to TTKSK (Jin et al., 2007). In this study, two durum monogenic lines, ST464-C1 and KL-B, postulated to carry $\mathrm{Sr} 13$, gave seedling ITs of $2+$ and $2++$ to TTKSK, respectively (Table 2). Both Langdon and its disomic substitution of chromosome 5D for 5B gave similar ITs 2C and 2+ to TTKSK similarly to ST464-C1 and KL-B (Table 2). Thus, all six Langdon-Ae. speltoides had lower ITs than could be explained by the presence of $\operatorname{Sr} 13$ alone, suggesting that they carry an additional gene(s) controlling resistance to TTKSK and other races.

The wild relative species of cultivated wheats are valuable sources of novel genes for many desirable wheat traits. Due to their wild grassy characteristics, related species are usually not suitable for direct evaluation and characterization of those traits. However, the wheat-alien species derivatives such as amphiploids or partial amphiploids, and chromosome addition, substitution, and translocation lines are usually in semidomesticated or domesticated backgrounds and can be easily used for evaluation and characterization. Such materials have played an important role in wheat improvement (Jones et al., 1995; Jiang et al., 1994). The sources of resistance to Ug99 and other races identified in this study will be useful in resistance breeding in both common and durum wheat. Even though it is difficult to utilize the resistant lines identified in this study, including wheat-alien species amphiploids and diosomic addition lines, directly in wheat breeding, they can be hybridized with wheat for chromosome manipulation and elimination enabling the retention of chromosome regions with desirable attributes while eliminating the unwanted chromatin.

\section{Acknowledgments}

We thank Drs. Chao-Chien Jan and Lili Qi for critically reviewing the manuscript. This material is based on work supported by the USDA-ARS CRIS Project No. 5442-22000-033-00D and Cornell University Project "Durable Rust Resistance in Wheat".

\section{References}

Anderson, M.K., N.D. Williams, and S.S. Maan. 1971. Monosomic analyses of genes for stem rust resistance derived from Marquis and Reliance wheats. Crop Sci. 11:556-558.

Banks, P.M., S.J. Xu, R.R.-C. Wang, and P.J. Larkin. 1993. Varying chromosome composition of 56-chromosome wheat $\times$ Thinopyrum intermedium partial amphiploids. Genome 36:207-215.

Bluethner, W.D., V. Schubert, and D. Mettin. 1988. Instability in amphiploids and backcross derivatives of a Triticum aestivum $\times$ Aegilops caudata cross. p. 209-213. In T.E. Miller and R.M.D. Koebner (ed.) Proc. 7th Int. Wheat Genet. Symp. Inst. of Plant Science Research, Cambridge, UK.

Cauderon, Y., B. Saigne, and M. Dauge. 1973. The resistance to wheat rusts of Agropyron intermedium and its use in wheat improvement. p. 401-407. In E.R. Sears and L.M.S. Sears (ed.) Proc. 4th Int. Wheat Genet. Symp. Univ. of Missouri Agricultural Research Station, Columbia, MO. 
Charpentier, A. 1992. Production of disomic addition lines and partial amphiploids of Thinopyrum junceum on wheat. C. R. Acad. Sci. Paris 315:551-557.

Chen, P.D., L.L. Qi, B. Zhou, S.Z. Zhang, and D.J. Liu. 1995. Development and molecular cytogenetic analysis of wheatHaynaldia villosa 6VS/6AL translocation lines specifying resistance to powdery mildew. Theor. Appl. Genet. 91:1125-1128.

Dvořák, J., and D.R. Knott. 1974. Disomic and ditelosomic additions of diploid Agropyron elongatum chromosomes to Triticum aestivum. Can. J. Genet. Cytol. 16:399-417.

Faris, J.D., S.S. Xu, X. Cai, T.L. Friesen, and Y.Jin. 2008. Molecular and cytogenetic characterization of a durum wheat- Aegilops speltoides chromosome translocation conferring resistance to stem rust. Chromosome Res. 16:1097-1105.

Friebe, B., J. Jiang, W.J. Raupp, R.A. McIntosh, and B.S. Gill. 1996. Characterization of wheat-alien translocations conferring resistance to diseases and pests: Current status. Euphytica 91:59-87.

Friebe, B., V. Schubert, W.D. Blüthner, and K. Hammer. 1992. C-banding pattern and polymorphism of Aegilops caudata and chromosomal constitutions of the amphiploid T. aestivum-Ae. caudata and six derived chromosome addition lines. Theor. Appl. Genet. 83:589-596.

Heermann, R.M., and T.E. Stoa. 1956. New durum wheats resistant to 15B. N. Dakota Agric. Exp. Stn. Farm Res. 18:75-81.

Jiang, J., B. Friebe, and B.S. Gill. 1994. Recent advances in alien gene transfer in wheat. Euphytica 73:199-212.

Jin, Y., and R.P. Singh. 2006. Resistance in U.S. wheat to recent eastern African isolates of Puccinia graminis f. sp. tritici with virulence to resistance gene Sr31. Plant Dis. 90:476-480.

Jin, Y., R.P. Singh, R.W. Ward, R. Wanyera, M. Kinyua, P. Njau, T. Fetch, Z.A. Pretorius, and A. Yahyaoui. 2007. Characterization of seedling infection types and adult plant infection responses of monogenic Sr gene lines to race TTKS of Puccinia graminis f. sp. tritici. Plant Dis. 91:1096-1099.

Jin, Y., L.J. Szabo, and Z.A. Pretorius. 2008a. Virulence variation within the Ug99 lineage. p. 4-6. In R. Appels, R. Eastwood, E. Lagudah, P. Langridge, M. Mackay, L. McIntye, and P. Sharp (ed.) Proc. 11th Int. Wheat Genet. Symp. Sydney Univ. Press, Sydney, Australia.

Jin, Y., L.J. Szabo, Z.A. Pretorius, R.P. Singh, R. Ward, and T. Fetch, Jr. 2008b. Detection of virulence to resistance gene Sr24 within race TTKS of Puccinia graminis f. sp. tritici. Plant Dis. 92:923-926.

Jin, Y., L.J. Szabo, M. Rouse, T. Fetch, Jr., Z.A. Pretorius, R. Wanyera, and P. Njau. 2009. Detection of virulence to resistance gene Sr36 within race TTKS lineage of Puccinia graminis f. sp. tritici. Plant Dis. 93:367-370.

Jones, S.S., T.D. Murray, and R.E. Allan. 1995. Use of alien genes for the development of disease resistance in wheat. Annu. Rev. Phytopathol. 33:429-443.

Joppa, L.R., and N.D. Williams. 1988. Langdon durum disomic substitution lines and aneuploid analysis in tetraploid wheat. Genome 30:222-228.

Kibirige-Sebunya, I., and D.R. Knott. 1983. Transfer of stem rust resistance to wheat from an Agropyron chromosome having a gametocidal effect. Can. J. Genet. Cytol. 25:215-221.

Klindworth, D.L., J.D. Miller, Y. Jin, and S.S. Xu. 2007. Chromosomal locations of genes for stem rust resistance in monogenic lines derived from tetraploid wheat accession ST464. Crop Sci. 47:1441-1450.

Klindworth, D.L., J.D. Miller, and S.S. Xu. 2006. Registration of 'Rusty' durum wheat. Crop Sci. 46:1012-1013.
Knott, D.R. 1962. The inheritance of rust resistance: IX. The inheritance of resistance to races $15 \mathrm{~B}$ and 56 of stem rust in the wheat variety Khapstein. Can. J. Plant Sci. 42:415-419.

Knott, D.R. 1988. The chromosome location of four recombinants between Agropyron chromosome $7 \mathrm{el}_{2}$ and a wheat chromosome. Genome 30:97-98.

Knott, D.R., J. Dvořák, and J.S. Nanda. 1977. The transfer to wheat and homoeology of an Agropyron elongatum chromosome carrying resistance to stem rust. Can. J. Genet. Cytol. 19:75-79.

Leonard, K.J., and L.J. Szabo. 2005. Stem rust of small grains and grasses caused by Puccinia graminis. Mol. Plant Pathol. 6:99-111.

Li, J., D.L. Klindworth, F. Shireen, X. Cai, J. Hu, and S.S. Xu. 2006. Molecular characterization and chromosome-specific TRAP marker development for Langdon durum D-genome disomic substitution lines. Genome 49:1545-1554.

Li, X.-M., B.S. Lee, A.C. Mammadov, B.-C. Koo, I.W. Mott, and R.R.-C. Wang. 2007. CAPS markers specific to $\mathrm{E}^{\mathrm{b}}, \mathrm{E}^{\mathrm{e}}$, and $\mathrm{R}$ genomes in the tribe Triticeae. Genome 50:400-411.

McIntosh, R.A., C.R. Wellings, and R.F. Park. 1995. Wheat rusts: An atlas of resistance genes. CSIRO Publications, East Melbourne, Australia.

McIntosh, R.A., Y. Yamazaki, J. Dubcovsky, J. Rogers, C. Morris, D.J. Somers, R. Appels, and K.M. Devos. 2008. Catalogue of gene symbols for wheat: MacGene 2008. Available at http:// www.shigen.nig.ac.jp/wheat/komugi/genes/download.jsp (verified 27 Aug. 2009). Committee for the National BioResource Project (NBRP)/KOMUGI, Japan.

Nazari, K., M. Mafi, A. Yahyaoui, R.P. Singh, and R.F. Park. 2009. Detection of wheat stem rust (Puccinia graminis $\mathrm{f}$. $\mathrm{sp}$. tritici) race TTKSK (Ug99) in Iran. Plant Dis. 93:317.

Oliver, R.E., X. Cai, R.R.-C. Wang, S.S. Xu, and T.L. Friesen. 2008. Resistance to tan spot and Stagonospora nodorum blotch in wheat-alien species derivatives. Plant Dis. 92:150-157.

Oliver, R.E., X. Cai, S.S. Xu, X. Chen, and R.W. Stack. 2005. Wheat-alien species derivatives: A potential source of novel resistance to Fusarium head blight in wheat. Crop Sci. 45:1353-1360.

Oliver, R.E., S.S. Xu, R.W. Stack, T.L. Friesen, Y. Jin, and X. Cai. 2006. Molecular cytogenetic characterization of four partial wheat-Thinopyrum ponticum amphiploids and their reactions to Fusarium head blight, tan spot, and Stagonospora nodorum blotch. Theor. Appl. Genet. 112:1473-1479.

Pretorius, Z.A., R.P. Singh, W.W. Wagoire, and T.S. Payne. 2000. Detection of virulence to wheat stem rust resistance gene $S r 31$ in Puccinia graminis f. sp. tritici in Uganda. Plant Dis. 84:203.

Roelfs, A.P., and J.W. Martens. 1988. An international system of nomenclature for Puccinia graminis f. sp. tritici. Phytopathology 78:526-533.

Singh, R.P., D.P. Hodson, Y. Jin, J. Huerta-Espino, M.G. Kinyua, R. Wanyera, P. Njau, and R.W. Ward. 2006. Current status, likely migration and strategies to mitigate the threat to wheat production from race Ug99 (TTKS) of stem rust pathogen. CAB Rev. Perspect. Agric. Vet. Sci. Nutr. Nat. Res. 54:1-13.

Singh, R.P., J.H. Huerta-Espino, Y. Jin, S. Herrera-Foessel, P. Njau, R. Wanyera, and R.W. Ward. 2008. Current resistance sources and breeding strategies to mitigate Ug99 threat. p. 7-9. In R. Appels, R. Eastwood, E. Lagudah, P. Langridge, M. Mackay, L. McIntye, and P. Sharp (ed.) Proc. 11th Int. Wheat Genet. Symp. Sydney Univ. Press, Sydney, Australia.

Stakman, E.C., D.M. Steward, and W.Q. Loegering. 1962. Identification of physiologic races of Puccinia graminis var. tritici. USDA ARS E-617. U.S. Gov. Print. Off., Washington, DC. 
Sun, S.C. 1981. The approach and methods of breeding new varieties and new species from Agrotriticum hybrids. Acta Agron. Sin. 7:51-58.

The, T.T., and E.P. Baker. 1970. Homoeologous relationships between two Agropyron intermedium chromosomes and wheat. Wheat Inf. Serv. 31:29-31.

Wang, R.R.-C., X.-M. Li, Z.-M. Hu, J.-Y. Zhang, S.R. Larson, X.-Y. Zhang, C.M. Grieve, and M.C. Shannon. 2003. Development of salinity-tolerant wheat recombinant lines from a wheat disomic addition line carrying a Thinopyrum junceum chromosome. Int. J. Plant Sci. 164:25-33.

Wanyera, R., M.G. Kinyua, Y. Jin, and R.P. Singh. 2006. The spread of stem rust caused by Puccinia graminis $\mathrm{f}$. sp. tritici, with virulence on Sr31 in wheat in eastern Africa. Plant Dis. 90:113.

Xu, S.J., and L.R. Joppa. 2000. First-division restitution in hybrids of Langdon durum disomic substitution lines with rye and Aegilops squarrosa. Plant Breed. 119:233-241.

Xu, S.S., I.S. Dundas, M.O. Pumphrey, Y. Jin, J.D. Faris, X. Cai, L.L. Qi, B.R. Friebe, and B.S. Gill. 2008. Chromosome engineering to enhance utility of alien-derived stem rust resistance. p. 12-14. In R. Appels, R. Eastwood, E. Lagudah, P.
Langridge, M. Mackay, L. McIntye, and P. Sharp (ed.) Proc. 11th Int. Wheat Genet. Symp. Sydney Univ. Press, Sydney, Australia

Xue, X.-Z., and R.R.-C. Wang. 1999. Detection of Elymus rectisetus chromosome segments added to wheat by RAPD and genomic in situ hybridization. Acta Genet. Sin. 26:539-545.

Zhang, J.Y., X.M. Li, R.R.-C. Wang, A. Cortes, V. Rosas, and A. Mujeeb-Kazi. 2002. Molecular cytogenetic characterization of $\mathrm{E}^{\mathrm{b}}$-genome chromosomes in Thinopyrum bessarabicum disomic addition lines of bread wheat. Int. J. Plant Sci. 163:167-174.

Zhang, X.Y., Y.S. Dong, and R.R.-C. Wang. 1996a. Characterization of genomes and chromosomes in partial amphiploids of the hybrid Triticum aestivum $\times$ Thinopyrum ponticum by in situ hybridization, isozyme analysis, and RAPD. Genome 39:1062-1071.

Zhang, X.Y., A. Koul, R. Petroski, T. Ouellet, G. Fedak, Y.S. Dong, and R.R.-C. Wang. 1996b. Molecular verification and characterization of BYDV-resistant germ plasms derived from hybrids of wheat with Thinopyrum ponticum and Th. intermedium. Theor. Appl. Genet. 93:1033-1039. 